\title{
Pengendalian Kualitas Produksi Roma Sandwich Menggunakan Metode Statistik Quality Control (SQC) Dalam Upaya Menurunkan Reject di bagaian Packing
}

\section{SQC Method is Used on Roma Sandwich Production in Order to Reduce the Rejection on the Packing}

\author{
Tina Hernawati Suryatman', Muhamad Engkos Kosim, Siti Julaeha ${ }^{3}$ \\ 1,3. Program Studi Teknik Industri, Fakultas Teknik, Universitas Muhammadiyah Tangerang \\ 2. Program Studi Teknik Kimia, Fakultas Teknik, Universitas Muhammadiyah Jakarta \\ 1tinahernawati76@gmail.com, 2engkos.kosim@umj.ac.id,
}

\begin{abstract}
PT. Mayora Indah Tbk is a company engaged in the food and beverage industry sector. In carrying out its production activities, the company always strives to produce good products and suppress rejects. This study aims to determine the factors that cause the results of reject rome sandwich products and how to control the quality of rome sandwich biscuit products at PT. Mayora Indah Jatake 2 using statistical methods. Quality control analysis is performed using statistical methods such as check sheets, histograms, control maps, cause-effect diagrams and the Failure Mode Effect Analysis (FMEA) method. The results of the analysis using checksheets indicate that in the production process there is still a high biscuit reject of $19.28 \%$, then the results of the control map show that there is a very high and irregular fluctuating point indicating that the production process is still experiencing deviations, therefore it is still needed further analysis using fishbone diagram. From the analysis of cause and effect can be known the factors causing rejects are derived from human factors, methods, and materials. Furthermore based on the analysis using the FMEA method the main priority is improvement based on the highest RPN value that must be conducted by PT Mayora Indah, including making biscuit lines and lowering the packing table lower than the output of sandwiching machines with an RPN value of 168, making a standard Teflon diameter and revising the Teflon condition check every week with an RPN value of 105, and changing the stacking path from non-opposite direction to the opposite direction $R P N$ value of 72.
\end{abstract}

Keywords: Quality Control, Statistical Methods, Failure Mode Effect Analysis (FMEA), Reject, Risk Priority Number (RPN)

PT. Mayora Indah Tbk merupakan perusahaan yang bergerak dalam sector indusutri makanan dan minuman. Dalam menjalankan kegiatan produksinya, perusahaan selalu berupaya untuk menghasilkan produk yang baik dan menekan terjadinya reject. Penelitian ini bertujuan untuk mengetahui faktor-faktor penyebab terjadinya reject hasil biskuit roma sandwich dan bagaimana pengendalian kualitas produk biskuit roma sandwich di PT. Mayora Indah Jatake 2 dengan menggunakan metode statistik. Analasis pengendalian kualitas dilakukan menggunakan metode statistik berupa check sheet, histogram, peta kendali, diagram sebab-akibat dan metode Failure Mode Effect Analysis (FMEA). Hasil analisis menggunakan checksheet menunjukkan bahwa dalam proses produksi masih terdapat reject biskuit yang tinggi sebesar 19,28\%, kemudian hasil dari peta kendali menunjukan bahwa adanya titik berfluktuasi sangat tinggi dan tidak beraturan yang menunjukkan bahwa proses produksi masih mengalami penyimpangan, oleh sebab itu masih diperlukan analisia lebih lanjut dengan menggunakan diagram sebab-akibat (fishbone diagram). Dari analisis sebab-akibat dapat diketahui faktor penyebab penyimpangan/reject berasal dari faktor manusia, metode, dan material. Selanjutnya berdasarkan analisis menggunakan metode FMEA prioritas utama perbaikan berdasarkan nilai RPN tertinggi yang harus dilakukan oleh PT. Mayora Indah diantranya yaitu Membuat jalur biskuit dan menurunkan packing table lebih rendah dari output mesin sandwiching dengan nilai RPN sebesar 168, Membuat standar diameter teflon dan revisi pengecekan kondisi teflon di setiap minggu dengan nilai RPN sebesar 105, dan Merubah jalur stacking dari yang tidak berlawanan arah menjadi berlawanan arah nilai RPN sebesar 72

Kata Kunci: Pengendalian Kualitas, Metode Statistik, Failure Mode Effect Analysis (FMEA), Reject, Risk Priority Number (RPN) 


\section{PENDAhuluan}

\subsection{Latar Belakang}

Kemajuan dan perkembangan zaman merubah cara pandang konsumen dalam memilih sebuah produk yang diinginkan. Kualitas menjadi sangat penting dalam memilih produk disamping faktor harga yang bersaing. Suatu perusahaan tidak lepas dari konsumen serta produk yang dihasilkannya. Konsumen tentunya berharap bahwa barang yang dibelinya akan dapat memenuhi kebutuhan dan keinginannya sehingga konsumen berharap bahwa produk tersebut memiliki kondisi yang baik serta terjamin, maka dari itu perusahaan harus melihat serta menjaga agar kualitas produk yang dihasilkan terjamin serta diterima oleh konsumen serta dapat bersaing di pasar.

Pengendalian kualitas pada perusahaan baik perusahaan jasa maupun perusahaan manufaktur sangatlah diperlukan. Dengan kualitas jasa ataupun barang yang dihasilkan tentunya perusahaan berharap dapat menarik konsumen dan dapat memenuhi kebutuhan serta keinginan konsumen. Perbaikan kualitas dan perbaikan proses terhadap sistem produksi secara menyeluruh harus dilakukan jika perusahaan ingin menghasilkan produk yang berkualitas baik dalam waktu yang relatif singkat. Suatu perusahaan dikatakan berkualitas bila perusahaan tersebut mempunyai sistem produksi yang baik dengan proses terkendali. Melalui pengendalian kualitas (quality control) diharapkan bahwa perusahaan dapat meningkatkan efektifitas pengendalian dalam mencegah terjadinya produk cacat (defect prevention), sehingga dapat menekan terjadinya pemborosan dari segi material maupun tenaga kerja yang akhirnya dapat meningkatkan produktifitas

PT. Mayora Indah Tbk jatake 2 adalah Perusahaan yang bergerak di bidang industri makanan divisi biskuit yang berlokasi di jl. Industri Raya Blok C Jatake, Tangerang. Di PT. Mayora jtk 2 ini terdapat 8 line yang berproduksi diantaranya yaitu roma sandwich, slaio'lai, roma kelapa, malkits coklat, sari gandum, better, roma kelapa renceng, dan marrie susu. Dari hasil pengamatan yang telah dilakukan, maka didapatkan adanya permasalahan mengenai reject dibagian packing roma sandwich tinggi yaitu sebesar $18,18 \%$ yang mengakibatkan achievement produksi roma sandwich menurun. Berikut data reject produk biskuit roma sandwich selama periode Mei- Desember 2018 sebagai berikut:

Tabel 1. Jumlah Produksi, Reject Proses Dan Reject Hasil

\begin{tabular}{|c|l|c|c|c|c|c|}
\hline \multirow{2}{*}{ No } & \multirow{2}{*}{ Bulan } & \multirow{2}{*}{ Output } & \multicolumn{2}{|c|}{ Reject Proses } & \multicolumn{2}{c|}{ Reject Hasil } \\
\cline { 4 - 7 } & & & $\mathrm{Kg}$ & $\%$ & $\mathrm{Kg}$ & $\%$ \\
\hline 1 & Mei & 42.676 & 3.594 & $8,42 \%$ & 10.589 & $24,81 \%$ \\
\hline 2 & Juni & 50.669 & 4.234 & $8,36 \%$ & 11.924 & $23,53 \%$ \\
\hline 3 & Juli & 96.036 & 5.424 & $5,65 \%$ & 30.537 & $31,80 \%$ \\
\hline 4 & Agustus & 42.475 & 1.598 & $3,76 \%$ & 6.921 & $16,29 \%$ \\
\hline 5 & September & 96.018 & 4.836 & $5,04 \%$ & 31.636 & $32,95 \%$ \\
\hline 6 & Oktober & 114.153 & 4.771 & $4,18 \%$ & 17.86 & $15,65 \%$ \\
\hline 7 & November & 104.029 & 1.531 & $1,47 \%$ & 6.848 & $6,58 \%$ \\
\hline 8 & Desember & 159.313 & 2.275 & $1,43 \%$ & 11.946 & $7,50 \%$ \\
\hline & Total & $\mathbf{7 0 5 . 3 6 9}$ & $\mathbf{2 8 . 2 6 3}$ & $\mathbf{4 , 0 1 \%}$ & $\mathbf{1 2 8 . 2 6 1}$ & $\mathbf{1 8 , 1 8 \%}$ \\
\hline
\end{tabular}

Penelitian ini bertujuan untuk mengetahui faktor-faktor penyebab terjadinya reject hasil biskuit roma sandwich dan bagaimana pengendalian kualitas produk biskuit roma sandwich di PT. Mayora Indah Jatake 2 dengan menggunakan metode statistik.

\subsection{Landasan Teori}

Menurut Philip B. Crosby (1979) dalam jurnal Wahyudi Dan Kosasih (2017), kualitas adalah comformanceto requirement, yaitu sesuai dengan yang disyaratkan atau distandarkan. Suatu produk memiliki kualitas apabila sesuai dengan standar kualitas yang telah ditentukan. Standar kualitas meliputi bahan baku, proses produksi, dan produk jadi. 
Crosby terkenal dengan anjuran manajemen zero defect dan pencegahan, yang menentang tingkat kualitas yang dapat diterima secara statistik (acceptable quality level).

Menurut Davis (2001) dalam jurnal Handoko (2017), membuat definisi kualitas yang lebih luas cakupannya, yaitu kualitas merupakan suatu kondisi dinamis yang berhubungan dengan produk, jasa, manusia, proses, dan lingkungan yang memenuhi atau melebihi harapan. Pendekatan yang digunakan Davis ini menegaskan bahwa kualitas bukan hanya menekankan pada aspek hasil akhir, yaitu produk dan jasa tetapi juga menyangkut kualitas manusia, kualitas lingkungan.

Kata kualitas memiliki definisi yang berbeda dan bervariasi dari yang konvensional sampai yang lebih strategik. Definisi konvensional dari kualitas biasanya menggambarkan karakteristik langsung dari suatu produk, seperti : performansi (performance), keandalan (realibility), mudah dalam penggunaan (easeofuse), estetika (esthetics), dan sebagainya. Sedangkan definisi strategik menyatakan bahwa kualitas adalah segala sesuatu yang mampu memenuhi keinginan atau kebutuhan pelanggan (meeting the needs of customers) menurut Gaspersz dalam jurnal Amrina dan Fajrah (2015). Dalam mendefinisikan kualitas produk ada lima pakar utama dalam manajemen mutu terpadu (Total Quality Management) yang saling berbeda pendapat, tetapi maksudnya sama. Dibawah ini dikemukakan pengertian kualitas dari lima pakar TQM.

Dengan semakin banyaknya perubahan yang berkembang di indonesia saat ini, maka bagi manajemen kualitas produk menjadi lebih penting dari sbelumnya. Persaingan yang sangat ketat menjadikan pengusaha semakin menyadari pentingnya kualitas produk agar dapat bersaing dan mendapat pangsa pasar yang lebih besar. Perusahaan membutuhkan suatu cara yang dapat mewujudkan terciptanya kualitas yang baik pada produk yang dihasilkan serta menjaga konsistensinya agar tetap sesuai dengan tuntutan pasar yaitu dengan menerapkan sistem pengendalian kualitas (quality control) atas aktivitas proses yang dijalani.

Menurut Prihantoro (2012) dalam jurnal Handoko (2017), pengendalian kualitas adalah suatu sistem kendali yang efektif untuk mengoordinasikan usaha-usaha penjagaan kualitas, dan perbaikan mutu dari kelompok-kelompok dalam organisasi produksi, sehingga diperoleh suatu produksi yang sangat ekonomis serta dapat memuaskan kebutuhan dan keinginan konsumen. Tujuan akhir dari pengendalian kualitas adalah sebagai alat yang efektif dalam pengurangan variabilitas produk.

Tujuan utama pengendalian kualitas adalah untuk mendapatkan jaminan bahwa kualitas produk atau jasa yang dihasilkan sesuai dengan standar kualitas yang telah ditetapkan dengan mengeluarkan biaya yang ekonomis atau serendah mungkin.

Pengendalian kualitas tidak dapat dilepaskan dari pengendalian produksi, karena pengendalian kualitas merupakan bagian dari pengendalian produksi. Pengendalian produksi baik secara kualitas maupun kuantitas merupakan kegiatan yang sangat penting dalam suatu perusahaan. Hal ini disebabkan karena semua kegiatan produksi yang dilaksankan akan dikendalikan, supaya barang dan jasa yang dihasilkan sesuai dengan rencana yang telah ditetapkan.

Pengendalian kualitas secara statistik dengan menggunakan SQC (Statistical Quality Control) mempunyai 7 (tujuh) alat statistik utama yang dapat digunakan sebagai alat bantu untuk mengendalikan kualitas sebagaimana disebutkan juga oleh Heizer dan Render (2005) dikutip oleh Kartika (2013) dalam jurnal Devani dan Wahyuni, yaitu check sheet, histogram, control chart, diagram sebab akibat.

\section{METODOLOGI}

\section{Data dan Informasi Penelitian}

Penelitiaan ini dilakukan di PT. Mayora Indah Tbk, yang beralamat di Jl. Industri Jatake No. 7, Pasir Jaya, Jatiuwung Kota Tangerang, Banten 15135. Penelitian ini berfokus meminimalkan reject yang mengalami permasalahan dalam kualitas. Pengamatan ini akan dilakukan secara langsung ke lapangan dan bekerja sama dengan bagian produksi. 


\section{Jenis dan Sumber Data}

Jenis data yang digunakan dalam penelitian ini adalah data primer yang merupakan data yang diperoleh dari PT. Mayora Indah yang menjadi tempat penelitian. Data yang diperoleh berupa dat kuantitatif dan data kualitatif. Data kuantitatif yaitu data yang berupa angka-angka mengenai jumlah produksi dan data reject. Data kualitatif adalah data yang berupa informasi mengenai jenis reject, penyebab terjadi nya reject, bagian proses produksi dan bahan baku yang digunakan.

Sumber data keseluruhan diperoleh dari dalam institusi yang menjadi tempat penelitian. Data yang bersifat kuantitatif diperoleh dari dokumen / arsip bagian produksi dan bagian admin. Sedangkan data yang bersifat kualitatif diperoleh dari wawancara dan pengamatan secara langsung diperusahaan.

\section{Metode Pengumpulan Data}

Pada pengumpulan data menjelaskan tentang teknik pengumpulan data yang berisi pengamatan / observasi, wawancara, penelitian kepustakaan dan jenis data yang berisi data primer dan data sekunder.

\section{Teknik Pengumpulan Data}

Teknik pengumpulan data digunakan untuk mendapatkan informasi yang diperlukan dalam pemecahan masalah penelitian.

1. Metode wawancara: Metode wawancara merupakan cara untuk mendapatkan data daninformasi dengan tanya jawab secara langsung pada orang yang mengetahui tentang objek yang diteliti. Dalam hal ini adalah dengan pihak manajemen / karyawan yaitu data mengenai reject packing dan penyebabnya, proses produksi serta bahan baku yang digunakan.

2. Observasi: Yaitu pengamatan atau peninjauan secara langsung ditempat penelitian yaitu PT. Mayora Indah dengan mengamati sistem atau cara kerja pegawai yang ada, mengamati proses produksi dari awal sampe akhir.

3. Penelitian Kepustakaan (Library Research): Penelitian kepustakaan merupakan suatu metode yang dilakukan untuk mendapatkan pengetahuan dan landasan teoritis dalam menganalisis data dan permasalahan melalui karya tulis dan sumber-sumber lainnya sebagai bahan pertimbangan dalam penulisan tugas akhir ini.

\section{Jenis Pengumpulan Data}

Jenis pengumpulan data yang didapat secara langsung maupun tidak langsung guna menunjang dalam penelitian.

1. Data Primer: Data Primer adalah data yang diperoleh secara langsung dari pihak pihak yang terkait dibagian produksi. Data tersebut yaitu data reject hasil.

2. Data Sekunder: Data sekunder adalah data yang diperoleh secara tidak langsung dari pihak lain. Dalam hal ini data sekunder berupa literatur dari jurnal yang menunjang penelitian.

\section{Metode Analisis Data}

Pada tahap ini data yang sudah dikumpulkan dan diolah, kemudian dianalisis agar permasalahan yang sedang dibahas dapat terlihat lebih jelas permasalahnnya, sehingga pada nantinya akan memberikan kemudahan dalam menganalisis permasalahan ini. Analisa data dilakukan dengan menggunakan empat alat bantu dari metode SQC (Statistical Quality Control) yaitu check sheet, histogram, peta kendali (control chart), fishbone dan Failure Modes and Effect Analysis (FMEA) sebagai usulan perbaikan. Adapun langkah-langkah yang dilakukan adalah sebagai berikut:

1. Mengumpulkan data produksi dan produk rusak/reject (Check Sheet). Data yang diperoleh dari perusahaan terutama data produksi dan data produk rusak kemudian diolah menjadi tabel secara rapi dan terstruktur. Hal ini dilakukan agar memudahkan 
dalam memahami data tersebut hingga bisa dilakukan analisis lebih lanjut.

2. Membuat Histogram; Agar mudah membaca atau menjelaskan data dengan cepat, maka data tersebut perlu untuk disajikan dalam bentuk histogram yang berupa alat penyajian data secara visual dalam bentuk grafis balok yang memperlihatkan distribusi nilai yang diperoleh dalam bentuk angka.

3. Membuat Peta Kendali (control chart). Dalam menganalisa data penelitian ini, digunakan peta kendali (peta kendali proporsi kerusakan) sebagai alat untuk pengendalian proses secara statistik. Penggunaan peta kendali ini adalah dikarenakan pengendalian kualitas yang dilakukan bersifat atribut, serta data yang diperoleh yang dijadikan sampel pengamatan tidak tetap dan produk yang mengalami kerusakan tersebut dapat diperbaiki lagi sehingga harus di tolak (reject).

Adapun langkah-langkah dalam membuat peta kendali p sebagai berikut:

a. Menghitung Prosentase Kerusakan

$$
P=\frac{n p}{n} \text {. }
$$

b. Menghitung garis pusat/Central Line (CL)

$$
\mathrm{CL}=\bar{c}=\frac{\sum n p}{n} .
$$

c. Menghitung batas kendali atas atau Upper Control Limit (UCL)

$$
\mathrm{UCL}=\bar{c}+3 \sqrt{\bar{c}}
$$

d. Menghitung batas kendali bawah atau Lower Control Limit (LCL)

$$
\mathrm{LCL}=\bar{c}-3 \sqrt{\bar{c}}
$$

Apabila data yang diperoleh tidak seluruhnya berada dalam batas kendali yang ditetapkan, maka hal ini berarti data yang diambil belum seragam. Hal tersebut menyatakan bahwa pengendalian kualitas yang dilakukan oleh PT. Mayora Indah masih perlu adanya perbaikan. Hal tersebut dapat terlihat apabila ada titik yang berfluktuasi secara tidak beraturan yang menunjukkan bahwa proses produksi masih mengalami penyimpangan.

4. Mencari Faktor penyebab yang paling dominan dengan diagram sebab-akibat Setelah diketahui masalah utama yang paling dominan dengan menggunakan histogram, maka dilakukan analisa faktor kerusakan produk dengan menggunakan fishbone diagram, sehingga dapat menganalisis faktor-faktor apa saja yang menjadi penyebab reject biskuit tinggi.

5. Failure Modes and Effect Analysis (FMEA). FMEA merupakan salah satu alat yang digunakan untuk mengidentifikasi sebab dan akibat permasalahan pokok dan mengukurnya dalam beberapa kriteria standar yang telah ditetapkan sehingga nilai yang didapatkan dapat berguna untuk perbaikan di perusahaan. Beberapa langkah dalam melakukan proses FMEA adalah sebagai berikut:

1. Mengidentifikasi proses dan produk

2. Mendaftar masalah potensial yang dapat muncul

3. Menentukan nilai severity

Nilai tingkat keparahan terdiri dari rating 1-10, semakin parah akibat yang ditimbulkan maka semakin tinggi nilai rating yang diberikan

4. Menentukan nilai occurance

Nilai tingkat kemungkinan diberikan untuk setiap penyebab cacat dan juga memiliki nilai rating dari 1-10. Semakin sering terjadi cacat maka semakin tinggi nilai rating yang diberikan.

5. Menentukan nilai detection

Nilai detection terdiri dari rating 1-10. Semakin sulit penyebab cacat dideteksi, maka semakin tinggi nilai rating yang diberikan.

6. Menghitung Risk Priority Number (RPN) yang dinyatakan dengan persamaan: RPN $=$ severity $x$ occurance $x$ detection

7. Membuat daftar prioritas perbaikan untuk memperbaiki atau mencegah terjadinya potensi mode kegagalan (potential failure mode).

8. Membuat analisis usulan perbaikan (recommended action). 


\section{HASIL DAN PEMBAHASAN}

\section{Pengumpulan dan Pengolahan Data}

\section{Check Sheet}

Langkah pertama yang dilakukan untuk menganalisis pengendalian kualitas secara statistik adalah membuat tabel (check sheet) jumlah produksi, reject proses dan reject packing dengan standar mutu. Pembuatan tabel (Check sheet) ini berguna untuk mempermudah proses pengumpulan data serta analisis.

Berikut merupakan data reject produk roma sandwich dibagian packing yang diperoleh. Data ini adalah data produksi selama delapan bulan berturut-turut yang dihasilkan setiap bulan (Mei-Des 2018)

Tabel 2. Jumlah Produksi, Reject Proses dan Reject Hasil Per Bulan Produk Biskuit Roma Sandwich Tahun 2018

\begin{tabular}{|c|l|c|c|c|c|c|}
\hline \multirow{2}{*}{ No } & \multirow{2}{*}{ Bulan } & \multirow{2}{*}{ Output } & \multicolumn{2}{c|}{ Reject Proses } & \multicolumn{2}{c|}{ Reject Hasil } \\
\cline { 4 - 7 } & & $\mathbf{K g}$ & $\mathbf{\%}$ & Kg & $\mathbf{\%}$ \\
\hline 1 & Mei & 42.676 & 3.594 & $8,42 \%$ & 10.589 & $24,81 \%$ \\
\hline 2 & Juni & 50.669 & 4.234 & $8,36 \%$ & 11.924 & $23,53 \%$ \\
\hline 3 & Juli & 96.036 & 5.424 & $5,65 \%$ & 30.537 & $31,80 \%$ \\
\hline 4 & Agustus & 42.475 & 1.598 & $3,76 \%$ & 6.921 & $16,29 \%$ \\
\hline 5 & September & 96.018 & 4.836 & $5,04 \%$ & 31.636 & $32,95 \%$ \\
\hline 6 & Oktober & 114.153 & 4.771 & $4,18 \%$ & 17.86 & $15,65 \%$ \\
\hline 7 & November & 104.029 & 1.531 & $1,47 \%$ & 6.848 & $6,58 \%$ \\
\hline 8 & Desember & 159.313 & 2.275 & $1,43 \%$ & 11.946 & $7,50 \%$ \\
\hline & Total & $\mathbf{7 0 5 . 3 6 9}$ & $\mathbf{2 8 . 2 6 3}$ & $\mathbf{4 , 0 1 \%}$ & $\mathbf{1 2 8 . 2 6 1}$ & $\mathbf{1 8 , 1 8 \%}$ \\
\hline
\end{tabular}

2. Histogram

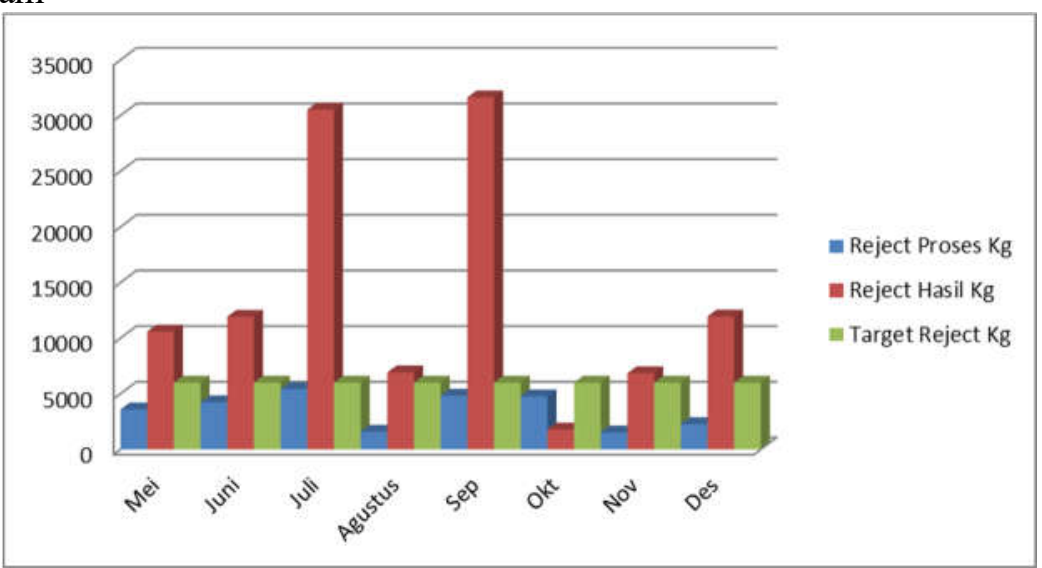

Gambar 4.5 Histogram reject proses \& reject hasil (kg/bln)

Dari histogram yang telah ditunjukkan pada gambar dapat bahwa reject hasil lebih tinggi dibandingkan dengan reject proses, adapun target reject keduanya yang telah ditentukan oleh perusahaan sebesar $6000 \mathrm{~kg} / \mathrm{bln}$. 
3. Peta Kendali (Control Chart)

Untuk hasil perhitungan control chart dapat dilihat pada tabel berikut:

Tabel 3. Perhitungan untuk Control Chart

\begin{tabular}{|c|c|c|c|c|c|}
\hline JUMLAH & JUMLAH & PROPORSI & \multirow[b]{2}{*}{ CL } & \multirow[b]{2}{*}{ UCL } & \multirow[b]{2}{*}{$\mathbf{L C L}$} \\
\hline PRODUKSI & $\begin{array}{c}\text { REJECT } \\
\text { (KG) }\end{array}$ & $\begin{array}{c}\text { REJECT } \\
\left(\mathbf{C}^{-}\right)\end{array}$ & & & \\
\hline 42,676 & 10,589 & 0.24812541 & 0.181835323 & 1.461099919 & -1.097429273 \\
\hline 50,669 & 11,924 & 0.23533127 & 0.181835323 & 1.461099919 & -1.097429273 \\
\hline 96,036 & 30,537 & 0.31797451 & 0.181835323 & 1.461099919 & -1.097429273 \\
\hline 42,475 & 6,921 & 0.16294291 & 0.181835323 & 1.461099919 & -1.097429273 \\
\hline 96,018 & 31,636 & 0.32947989 & 0.181835323 & 1.461099919 & -1.097429273 \\
\hline 114,153 & 17,860 & 0.15645669 & 0.181835323 & 1.461099919 & -1.097429273 \\
\hline 104,029 & 6,848 & 0.0658278 & 0.181835323 & 1.461099919 & -1.097429273 \\
\hline 159,313 & 11,946 & 0.07498446 & 0.181835323 & 1.461099919 & -1.097429273 \\
\hline 705,369 & 128,261 & & & & \\
\hline
\end{tabular}

Dari hasil perhitungan tabel di atas, maka selanjutnya dapat dibuat control chart yang dapat dilihat pada gambar berikut ini:

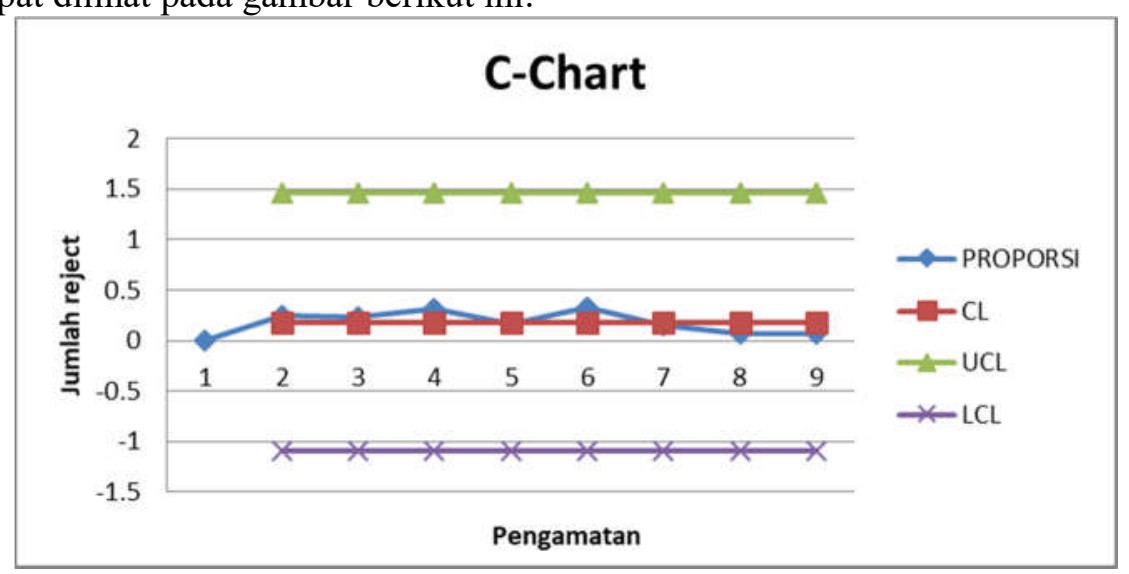

Gambar 2. Grafik Kendali C

Berdasarkan peta kendali diatas, dapat dilihat bahwa batas-batas pengendalian dipilih sedemikian rupa sehingga apabila proses terkendali, maka semua titik-titik sampel akan jatuh diantara UCL Maupun LCL. Selama titik-titik terletak didalam batas-batas pengendali, proses dianggap dalam keadaan terkendali. Namaun apabila terdapat data yang berada diluar batas kendali yang seharusnya, sehingga bisa dikatakan bahwa proses tidak terkendali atau menunjukan terdapat penyimpanangan atau masih banyak titik-titik yang barada diluar batas kendali dan titik tersebut berfluktuasi sangat tinggi dan tidak beraturan maka menunjukkan bahwa proses produksi masih mengalami penyimpangan. Penyimpangan tersebut disebabkan oleh faktor-faktor yang meliputi tenaga kerja, metode, dan material atau bahan baku. Oleh sebab itu masih diperlukan analisia lebih lanjut mengapa penyimpangan bisa terjadi dengan menggunakan diagram sebab-akibat (fishbone diagram) untuk mengetahui penyebab dari penyimpangan tersebut

\section{Diagram Sebab-Akibat (Fishbone Diagram)}

Sebagai alat bantu untuk mencari penyebab terjadinya kerusakan/reject tersebut, digunakan diagram sebab-akibat untuk menelusuri masing-masing jenis kerusakan/reject. Berikut ini adalah penggunaan diagram sebab-akibat untuk reject biskuit roma sandwich di area packing. 


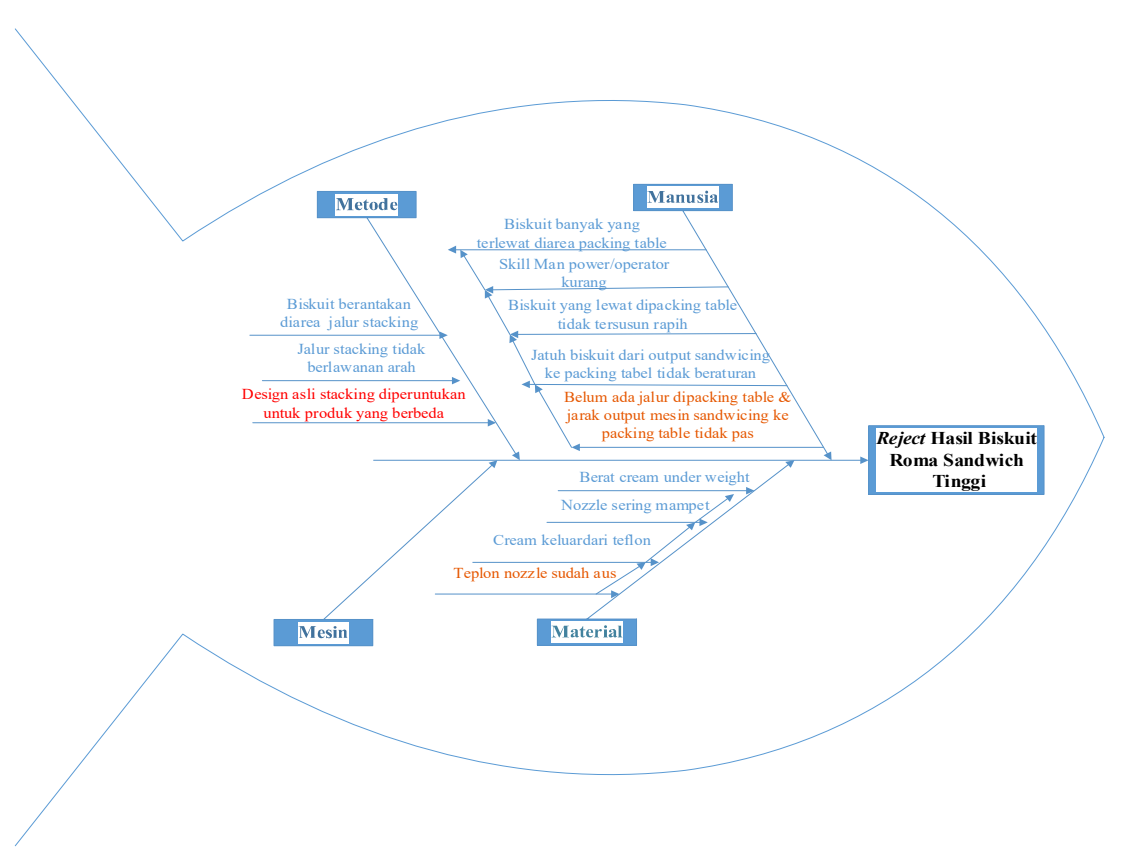

Gambar 3. Diagram Fishbone

Berdasarkan diagram fishbone diatas dapat disimpulkan bahwa penyebab terjadinya reject terjadi karena 3 faktor yaitu faktor manusia, faktor, material, dan faktor metode. Sedangkan faktor mesin tidak mempengaruhi terjadinya reject sehingga tidak termasuk faktor penyebab terjadinya reject biskuit.

5. Failure Mode and Effect Analysis (FMEA)

Setelah dilakukan analisa mengenai penyebab tingginya reject biskuit Roma Sandwich dengan fishbone diagram, selanjutnya menggunakan metode FMEA guna menentukan potential failure yang menyebabkan tingginya reject biskuit tahap awal yaitu menentukan kriteria penilaian SOD (severity, occurance, dan detection) dari beberapa mode kegagalan. Setelah itu dilakukan perhitungan untuk mendapatkan nilai RPN dengan mengalikan ketiga kriteria tersebut.

Berikut ini adalah perhitungan untuk mencari nilai RPN: jenis kegagalan pada proses yaitu biskuit banyak yang terlewat dengan nilai severity (5), detection (5), dan occurance (3) maka nilai RPN nya yaitu severity $\times$ detection $\times$ occurance $=5 \times 5 \times 3=75$, dan selanjutnya akan disajikan pada tabel 4. 
Tabel 4.3 Hasil Pengolahan FMEA

\begin{tabular}{|c|c|c|c|c|c|c|c|}
\hline Akibat & $\begin{array}{c}\text { Jenis kegagalan } \\
\text { pada proses }\end{array}$ & $\begin{array}{c}\text { Penyebab potensial } \\
\text { kegagalan }\end{array}$ & $\mathbf{S}$ & D & $\mathbf{O}$ & RPN & $\begin{array}{l}\text { Rekomendasi } \\
\text { Pengendalian }\end{array}$ \\
\hline \multirow{11}{*}{$\begin{array}{l}\text { Reject Hasil } \\
\text { Biskuit Roma } \\
\text { Sandwich Tinggi }\end{array}$} & \multirow{5}{*}{$\begin{array}{c}\text { biskuit banyak yang } \\
\text { terlewat dipacking } \\
\text { table }\end{array}$} & $\begin{array}{l}\text { biskuit yang lewat } \\
\text { dipacking table tidak } \\
\text { tersusun rapi }\end{array}$ & 5 & 5 & 3 & 75 & $\begin{array}{l}\text { Membuat jalur biskuit } \\
\text { agar dapat disusun } \\
\text { dengan rapi }\end{array}$ \\
\hline & & Skill manpower kurang & 3 & 4 & 2 & 24 & $\begin{array}{l}\text { Pemberian pelatihan dan } \\
\text { pengetahuan untuk } \\
\text { meningkatkan skill } \\
\text { manpower/operator }\end{array}$ \\
\hline & & $\begin{array}{l}\text { Jatuh biskuit dari output } \\
\text { sandwiching ke packing } \\
\text { table tidak beraturan }\end{array}$ & 3 & 5 & 3 & 45 & $\begin{array}{l}\text { Menurunkan packing } \\
\text { table lebih rendah dari } \\
\text { output mesin sandwiching }\end{array}$ \\
\hline & & $\begin{array}{l}\text { Belum ada jalur } \\
\text { dipacking table }\end{array}$ & 7 & 6 & 4 & 168 & $\begin{array}{l}\text { Membuat jalur biskuit } \\
\text { agar tidak banyak lagi } \\
\text { biskuit yang terlewat }\end{array}$ \\
\hline & & $\begin{array}{l}\text { Speed mesin } \\
\text { sandwiching cepat }\end{array}$ & 2 & 3 & 3 & 18 & $\begin{array}{l}\text { Mengurangi speed mesin } \\
\text { dan ikuti aturan yang } \\
\text { telah dibuat oleh } \\
\text { perusahaan }\end{array}$ \\
\hline & \multirow{4}{*}{$\begin{array}{c}\text { Berat cream under } \\
\text { weight }\end{array}$} & Cream keluar dari teflon & 3 & 3 & 2 & 18 & $\begin{array}{l}\text { Revisi pengecekan } \\
\text { kondisi teflon di setiap } \\
\text { minggu }\end{array}$ \\
\hline & & $\begin{array}{l}\text { Dimensi biskuit terlalu } \\
\text { lebar dan panjang }\end{array}$ & 7 & 5 & 2 & 60 & $\begin{array}{l}\text { Membuat standar } \\
\text { diameter teflon }\end{array}$ \\
\hline & & Teflon nozle sudah aus & 7 & 5 & 3 & 105 & $\begin{array}{l}\text { Mengganti teflon yang } \\
\text { baru }\end{array}$ \\
\hline & & Nozle sering mampet & 4 & 4 & 3 & 48 & $\begin{array}{l}\text { Membuat jadwal } \\
\text { pengecekan nozle agar } \\
\text { tidak mampet }\end{array}$ \\
\hline & \multirow{2}{*}{$\begin{array}{c}\text { Biskuit berantakan } \\
\text { diarea stacking }\end{array}$} & $\begin{array}{l}\text { Jalur stacking tidak } \\
\text { berlawanan }\end{array}$ & 6 & 4 & 3 & 72 & \multirow{2}{*}{$\begin{array}{l}\text { Merubah jalur stacking } \\
\text { dari yang tidak } \\
\text { berlawanan arah menjadi } \\
\text { barlawanan arah }\end{array}$} \\
\hline & & $\begin{array}{l}\text { Design asli stacking } \\
\text { diperuntukan untuk } \\
\text { produk yang berbeda }\end{array}$ & 6 & 4 & 3 & 72 & \\
\hline
\end{tabular}

Berdasarkan perhitungan nilai RPN masing-masing mode kegagalan, diperoleh nilai RPN tertinggi yaitu

1. Belum adanya jalur dipacking table dengan nilai RPN 168

2. Teflon nozle yang sudah aus dengan nilai RPN 105

3. Design asli stacking diperuntukan untuk produk yang berbeda dengan nilai RPN 72

Maka ketiga faktor ini lah yang menjadi penyebab reject biskuit roma sandwich tinggi, maka harus ada tindakan perbaikan atau perubahan desain untuk menekan reject yang disebabkan oleh ketiga faktor tersebut. Akan tetapi untuk mode kegagalan yang lainnya juga harus dilakukan pembenahan untuk dapat meningkatkan kualitas dan kuantitas produksi.

Usulan perbaikan dilakukan guna meminimalisir reject biskuit dibagian packing berdasarkan hasil perhitungan nilai RPN dan kemudian dilihat dari nilai RPN yang paling besar. Berdasarkan pengolahan data yang sudah dilakukan, maka rekomendasi perbaikan yang dapat dilakukan terlihat pada tabel 5 . 
Tabel 5. Rekomendasi Berdasarkan Nilai RPN Tertinggi

\begin{tabular}{|c|c|c|c|c|}
\hline No & Jenis kegagalan & Penyebab & Perbaikan & RPN \\
\hline 1. & $\begin{array}{l}\text { Biskuit banyak } \\
\text { yang terlewat } \\
\text { dipacking table }\end{array}$ & $\begin{array}{l}\text { Belum ada jalur } \\
\text { packing table }\end{array}$ & $\begin{array}{l}\text { Membuat jalur biskuit } \\
\text { dan menurunkan } \\
\text { packing table lebih } \\
\text { rendah dari output } \\
\text { mesin sandwiching }\end{array}$ & 168 \\
\hline 2. & $\begin{array}{l}\text { Berat cream under } \\
\text { weight }\end{array}$ & $\begin{array}{l}\text { Teflon nozle sudah } \\
\text { aus }\end{array}$ & $\begin{array}{l}\text { Membuat standar } \\
\text { diameter teflon dan } \\
\text { revisi pengecekan } \\
\text { kondisi teflon di setiap } \\
\text { minggu }\end{array}$ & 105 \\
\hline 3. & $\begin{array}{l}\text { Biskuit berantakan } \\
\text { di area jalur } \\
\text { stacking }\end{array}$ & $\begin{array}{l}\text { Design asli dari } \\
\text { stacking } \\
\text { diperuntukan untuk } \\
\text { produk yang berbeda }\end{array}$ & $\begin{array}{l}\text { Merubah jalur stacking } \\
\text { dari yang tidak } \\
\text { berlawanan arah } \\
\text { menjadi berlawanan } \\
\text { arah }\end{array}$ & 72 \\
\hline
\end{tabular}

\section{SIMPULAN DAN SARAN \\ Kesimpulan}

Berdasarkan penenlitian yang dilakukan pada salah satu line di PT. Mayora indah Tbk yang berlokasi di jatake selama bulan Mei-Desember 2018 dan diolah serta dianalisa dengan alat bantu statistik dan metode FMEA sebagai usulan perbaikan, maka dapat diperoleh kesimpulan sebagai berikut:

1. Dari hasil analisa diagram sebab-akibat diketahui bahwa penyebab utama tingginya reject biskuit roma sandwich yaitu karena faktor manusia, faktor material dan faktor metode nya.

- Faktor manusia, penyebabnya yaitu biskuit yang terlewat diarea packing table, skill man power kurang, biskuit yang lewat dipacking table tidak tersusun rapi, jatuh biskuit dari output sandwiching ke packing table tidak beraturan, maka root case nya yaitu Belum adanya jalur dipacking table dan jarak output mesin sandwiching ke packing table tidak pas.

- Faktor material, penyebabnya yaitu berat cream under weight, nozzle sering mampet, cream keluar dari Teflon, maka root case dari faktor material yaitu Teflon nozzle sudah aus/rusak.

- Faktor metode, penyebabnya yaitu biskuit berantakan diarea jalur stacking, jalur stacking tidak berlawanan arah, maka penyebab utama dari faktor metode ini yaitu karena design asli stacking diperuntukan untuk produk yang berbeda.

Bedasarkan pengolahan yang telah dilakukan maka dapat disimpulkan beberapa penyebab yang menjadi prioritas utama dilakukannya perbaikan karena memang penyebab tersebut memiliki nila RPN tertinggi dibandingkan dengan faktor penyebab yang lainnya.

- Belum adanya jalur dipacking table dengan nilai RPN yang dihasilkan sebesar 168

- Teflon nozzle yang sudah aus, nilai RPN yang dihasilkan sebesar 105

- Design asli stacking diperuntukan untuk produk yang berbeda dengan nilai RPN yang dihasilkan sebesar 72 
Usulan perbaikan yang dibuat berdasarkan nilai RPN yang tertinggi antara lain membuat jalur biskuit dan menurunkan packing table lebih rendah dari output mesin sandwiching, membuat standar diameter Teflon dan revisi pengecekan kondisi Teflon disetiap minggu, dan yang terakhir yaitu merubah metode jalur stacking dari yang tidak berlawanan menjadi berlawanan.

2. Berdasarkan hasil peta kendali dapat dilihat bahwa ternyata kualitas produk berada didalam batas kendali yang seharusnya. Hal ini dapat dilihat pada grafik yang menunjukan bahwa titik-titik yang berada didalam batas kendali dan beraturan. Hal ini merupakan indikasi bahwa proses berada dalam keadaan terkendali atau tidak mengalami penyimpangan.

\section{Saran}

1. Berdasarkan analisis menggunakan alat bantu statistik yang telah dilakukan, perusahaan dapat melakukan perbaikan kualitas dengan memfokuskan perbaikan pada reject biskuit yang disebabkan oleh faktor antara lain; manusia, metode, dan material. Setelah mengetahui penyebab kerusakan atau reject, maka tindakan selanjutnya yaitu melakukan pencegahan untuk memininalisir terjadinya reject.

2. Penerapan pengendalian kualitas produksi biskuit roma sandwich harus dipertahankan agar produksi yang dihasilkan dapat memenuhi standar Nasional maupun Internasional, dan untuk mencapai hasil yang maksimal, sebaiknya penerapan kualitas harus diperhatikan segala faktor yang mempengaruhi pada kualitas produksi.

3. Saran yang dibuat untuk perusahaan dalam upaya menurunkan reject biskuit dibagian packing sehingga dapat meningkatkan achievement dan produktifitas perusahaan adalah dengan melakukan perbaikan secara continue, lebih memperhatikan lingkungan kerja, kondisi karyawan/operator dan kinerja karyawan/operator. Perbaikan yang telah dibuat dapat diterapkan untuk membantu perusahaan dalam mencapai target yang di tuju. Akan tetapi semua itu bisa benar-benar membantu jika ada action yang dilakukan perusahaan yang secara continue. Karena semua akan menjadi tidak berguna ketika tidak adanya aksi nyata yang dilakukan perusahaan untuk menanggulangi permasalahan mengenai reject.

\section{DAFTAR PUSTAKA}

Banker, K., Patel, A., \& Patel, D. (2014). Implementation Of Statistical Quality Control (S.Q.C.) In Welded Stainless Steel Pipe Manufacturing Industry. IJRET: International Journal of Research in Engineering and Technology eISSN: 2319-1163 Vol.03, 270-273.

D.BHOSALE, S., Shilwant, \& Patil. (2013). Quality Improvment In Manufacturing Processes Using SQC Tools. International Journal Of Engineering Research And Aplications (IJERA) ISSN: 2248-9622 Vol, 3, 832 - 837.

Devani, V., Fitri, \& Wahyuni. (2016). Pengendalian Kualitas Kertas Dengan Menggunakan Statistical Process Control Di Paper Machine 3. Jurnal Ilmiah Teknik Industri eISSN 2460-4038, Vol.15, 87-93.

Dewi, N. W., Mulyani, S., \& Arnata, I. W. (2016). Pengendalian Kualitas Atribut Kemasan Menggunakan Metode Failure Mode Effect Analysis (FMEA) Pada Proses Produksi Air Minum Dalam Kemasan. Jurnal Rekaya dan Manajemen Argoindustri ISSN: 2503-488X, Vol. 4. No. 3, 149-160.

Fadil, M., \& Yunus, M. (2017). A Critical Assessment on the Implementation of Statistical Quality Control Tool Among SMES Food Industry in Malaysia. International Journal of Academic Research in Business and Social Sciences Vol. 7, No. 10 ISSN: 2222-6990, 467-477.

Handoko, A. (2017). Implementasi Pengendalian Kualitas Dengan Menggunakan Pendekatan PDCA Dan Seven Tools Pada PT. Rosandex Putra Perkasa Di Surabaya. Jurnal Ilmiah Mahasiswa Universitas Surabaya Vol.6 No.2, 1329-1347.

Kaban, R. (2014). Pengendalian Kualitas Kemasan Plastik Pouch Menggunakan Statistical 
Process Control (SPC) Di PT. Incasi Raya Padang . Jurnal Optimasi Sistem Industri, vo 13 No. $1,518-547$.

Nasution, M. (2005). Total Quality Management. Jakarta: PT. Gramedia Pustaka Utama. Syukron, A., \& Kholil, M. (2014). Pengantar Teknik Industri. Yogyakarta: Graha Ilmu.

Ratri, E. M., Bambang, E., \& Singgih, M. (2018). Peningkatan Kualitas Produk Roti Manis Pada PT Indoroti Prima Cemerlang Jember Berdasarkan Metode Statistical Proses Control (SPC) Method And Failure Mode And Effect Analysis (FMEA Method). ejournal Ekonomi Bisnis dan Akutansi ISSN 2355-4665 Vol.5 (1), 200-207.

Riswan, Nana, A., \& Renosari, P. (2017). Pengendalian Kualitas Dengan Metode Failure Mode Effect Analysis (FMEA) Untuk Mengurangi Cacat Produk Pada Hasil Produksi Grass Block Lubang Lima. Prosiding Teknik Industri ISSN: 2460-7200 Vol. 3 No.2, 207-214.

Tahit, S., Hasni, R. A., \& Bakhtiar. (2013). Analisa Pengendalian Kualitas dengan Menggunakan Metode Statistical Quality Control (SQC). Malikussaleh Industrial Engineering Journal Vol.2 No.1 ISSN 2302 934X, 29-36.

Librelato, T. P. et al. (2014) "A Process Improvement Approach based on the Value Stream Mapping and the Theory of Constraints Thinking Process," Business Process Management Journal, 20(6), hal. 922-949. doi: 10.1108/BPMJ-07-2013-0098.

Ruiz-de-Arbulo-Lopez, P., Fortuny-Santos, J. dan Cuatrecasas-Arbós, L. (2013) "Lean Manufacturing: Costing the Value Stream," Industrial Management \& Data Systems, 113(5), hal. 647-668. doi: 10.1108/02635571311324124.

wahyudi, M. K. (2017). Menanggulangi Wheel House Defect Spot Tajam Pada Jalur Side Member D176 DI PT. XYZ Dengan Metode PDCA. Jurnal Integrasi Sistem Industri Vol. 4 No. 2 Agustus 2017, 85-91. 